\title{
Canadian M.D.-Ph.D. Programs Produce Impactful Physician-Scientists: The McGill Experience
}

\author{
Tianwei E. Zhou, ${ }^{1,2,3,4}$ Paul A. Savage, ${ }^{1,5,6}$ and Mark J. Eisenberg ${ }^{1,7}$ \\ ${ }^{1}$ Faculty of Medicine, McGill University, Montréal, QC, Canada H3G $1 Y 6$ \\ ${ }^{2}$ Department of Pharmacology and Therapeutics, McGill University, Montréal, QC, Canada H3G $1 Y 6$ \\ ${ }^{3}$ CHU Sainte-Justine Hospital, University of Montréal, Montréal, QC, Canada H3T 1C5 \\ ${ }^{4}$ Hôpital Maisonneuve-Rosemont Research Center, University of Montréal, Montréal, QC, Canada H1T 2M4 \\ ${ }^{5}$ Department of Experimental Medicine, McGill University, Montréal, QC, Canada H3A 1A3 \\ ${ }^{6}$ Rosalind \& Morris Goodman Cancer Research Centre, McGill University, Montréal, QC, Canada H3A 1A3 \\ ${ }^{7}$ Divisions of Cardiology and Clinical Epidemiology, Jewish General Hospital, McGill University, Montréal, QC, Canada H3T 1E2 \\ Correspondence should be addressed to Mark J. Eisenberg; mark.eisenberg@mcgill.ca
}

Received 29 February 2016; Accepted 9 May 2016

Academic Editor: Jaimo Ahn

Copyright (C) 2016 Tianwei E. Zhou et al. This is an open access article distributed under the Creative Commons Attribution License, which permits unrestricted use, distribution, and reproduction in any medium, provided the original work is properly cited.

\begin{abstract}
On June 18, 2015, the Canadian Institutes of Health Research (CIHR) announced that it would terminate funding to M.D.-Ph.D. programs due to budget constraints, against the recommendations from two advisory panels. CIHR's M.D.-Ph.D. program grants, which amounted to an annual average of $\$ 1.8$ million in the form of 14 six-year studentships, represent only $0.15 \%$ of CIHR's $\$ 1.2$ billion operating budget. As over half of M.D.-Ph.D. trainees are dependent on these studentships, this poses a threat to physicianscientist training in Canada. In response to the current volatile funding climate, we surveyed McGill University's M.D.-Ph.D. program alumni to assess its success in producing physician-scientists. In this program, $60.0 \%$ of graduates who have completed training have become physician-scientists, the majority being retained in Canada. These individuals have attained positions with sufficiently protected time for research and had grant success and significant publications for early- to mid-career investigators. This suggests that the current M.D.-Ph.D. system is an effective way of producing competent physician-scientists. As physician-scientists have remarkably contributed to Canadian healthcare innovation despite making up a fraction of physicians and researchers, vulnerability in the M.D.-Ph.D. pipeline would invariably affect the health of Canadians.
\end{abstract}

\section{Introduction}

M.D.-Ph.D. programs are one of the structured training paths involving both medicine and research, with the goal of producing physician-scientists uniquely poised to bridge the gap between research and clinical practice. Despite making up only $3-4 \%$ of all physicians, physician-scientists have remarkably contributed to healthcare innovation in Canada and abroad.

CIHR's M.D.-Ph.D. program grants, which amounted to an annual average of $\$ 1.8$ million in the form of 14 sixyear studentships, represented $0.15 \%$ of CIHR's $\$ 1.3$ billion operating budget. On June 18, 2015, the Canadian Institutes of Health Research (CIHR) announced that it would unilaterally terminate funding to M.D.-Ph.D. programs due to budget constraints, against the recommendations from two advisory panels [1]. The M.D.-Ph.D. community has widely questioned the basis for this decision [2, 3]. In 2010, 88 of 170 (52\%) trainees across the 13 M.D.-Ph.D. programs in Canada relied on CIHR M.D.-Ph.D. studentships [4]. Furthermore, Yoon et al. found that financial support was associated with program satisfaction among physicianscientist trainees, further suggesting that these funding cuts will have profound implications for physician-scientist training in Canada [5]. This is especially concerning in light of the reported decline in the number of physician-scientists [6]. Meanwhile, the 2013 CIHR Strategy for Patient-Oriented Research External Advisory Committee on Training and 
Career Development Report (SPOR Report) pointed out that the absence of outcome data has made assessment of the relative impact of M.D.-Ph.D. programs difficult [7]. Therefore, in response to the current volatile funding climate and the paucity of M.D.-Ph.D. outcome data, we surveyed McGill University's M.D.-Ph.D. program alumni to assess its success in producing physician-scientists.

\section{Materials and Methods}

Surveys were performed using an online form and consisted of a balanced combination of 45 open- and closed-ended questions. These questions aimed to assess demographic information, current training or employment status, research interests, research output metrics, and training experience in McGill's M.D.-Ph.D. program. The survey was sent to 41 alumni who were enrolled in the combined program between 1985 and 2015.

\section{Results and Discussion}

Since 1995, 41 students have completed the program [8], $73.8 \%$ of whom responded to our survey $(88.9 \%$ response rate for residents, $77.8 \%$ for fellows, and $65.2 \%$ for posttrainees). Of the trainees who have been in the program since the inception of the CIHR M.D.-Ph.D. stipend in 1995, 78.8\% have utilized this funding at some point during their training. The majority of alumni $(76.7 \%)$ have remained in Canada, most notably in Ontario (33.3\%) and Quebec (30.0\%), with the rest settled in US $(23.3 \%)$. These proportions were maintained in both the trainee (currently a resident, clinical or research fellow) and posttrainee subpopulations $(80.0 \%$ in Canada) as well as for those who became physician-scientists (77.7\% in Canada). Although $26.7 \%$ of the program graduates are women, this trend has changed over time. Whereby $10 \%$ of graduates were women prior to the year 2000, women account for $42.9 \%$ of graduates since 2000 . With an apparent gender shift in medicine as previously reported [9], we anticipate a higher proportion of women in future cohorts.

Half of our alumni remain in the training pipeline. After graduating, most enroll in residency (96.7\%), followed by clinical (95.7\%) and research (57.1\%) fellowships, resulting in an average of 7.2 years (SD: 2.2) of postgraduate training for those who went on to become physician-scientists. Of the 15 respondent alumni who have completed training, $60.0 \%$ have become physician-scientists (defined as attending physician and principal investigator) with the remaining taking on careers as pure attending-physicians $(33.3 \%)$ or scientific investigators (6.7\%). All respondents have remained at academic centres.

We further assessed research productivity of our physician-scientist alumni (Table 1). The mean percent of protected research time was $49.0 \%( \pm 19.4)$. They are well funded, with $88.9 \%$ being primary investigators on a research grant, 55.5\% holding operating grants from federal funding bodies (e.g., CIHR, National Institutes of Health (NIH)), and $77.8 \%$ holding multiple ongoing grants. Their average number of publications was 38.7 (SD: 32.4). Moreover,
TABLE 1: Physician-scientist research.

\begin{tabular}{|c|c|}
\hline Clinician-investigator research & $n(\%)$ \\
\hline \multicolumn{2}{|l|}{ Protected research time, $\%$} \\
\hline$<25$ & $1(11.1)$ \\
\hline $25-49$ & $3(33.3)$ \\
\hline$\geq 50$ & $5(55.6)$ \\
\hline Mean \pm SD & $49.0 \pm 19.4$ \\
\hline \multicolumn{2}{|l|}{ Primary investigator on grant } \\
\hline Yes & $8(88.9)$ \\
\hline No & $1(11.1)$ \\
\hline \multicolumn{2}{|l|}{ Research grants } \\
\hline CIHR/NIH & $5(55.5)$ \\
\hline Multiple ongoing grants & $7(77.8)$ \\
\hline \multicolumn{2}{|l|}{ Publications ${ }^{*}$} \\
\hline$<25$ & $3(33.3)$ \\
\hline $25-50$ & $5(55.5)$ \\
\hline$>50$ & $1(11.1)$ \\
\hline Mean \pm SD & $39.6 \pm 31.4$ \\
\hline \multicolumn{2}{|l|}{$H$-index ${ }^{*}$} \\
\hline$<10$ & $2(22.2)$ \\
\hline $10-30$ & $6(66.6)$ \\
\hline$>30$ & $1(11.1)$ \\
\hline Mean \pm SD & $15.9 \pm 12.8$ \\
\hline \multicolumn{2}{|l|}{ Specialty } \\
\hline Neurology & $2(22.2)$ \\
\hline Pediatrics & $2(22.2)$ \\
\hline Anatomical pathology & $1(11.1)$ \\
\hline Internal medicine & $1(11.1)$ \\
\hline Neurosurgery & $1(11.1)$ \\
\hline Plastic surgery & $1(11.1)$ \\
\hline Radiology & $1(11.1)$ \\
\hline
\end{tabular}

${ }^{*}$ As of Sept 7, 2015.

their mean $H$-index, a measure of productivity and citation impact for a researcher, is 18 (SD: 13.7).

Importantly, our alumni are not confined to a few medical disciplines but rather have made their impact across various specialties (Table 2). Several alumni provide salient examples of the translational impact of M.D.-Ph.D. graduates, including one that has pushed a microarray-based breast cancer subtyping scheme into one that is compatible with the clinical specimens and may be used to spare women of chemotherapy [10]. Another has developed intraoperative spectroscopic methods to better define tumor margins in neurosurgery, a novel technique he has rapidly moved into a clinical trial [11]. Considering they have attained independent academic positions for 4-15 years (mean: 8.2 ; SD: 3.7 ), they have demonstrated significant research productivity as earlyto mid-career physician-scientists.

To our knowledge, our survey is the first outcome study for a Canadian M.D.-Ph.D. program. As an intermediately sized program with a typical curriculum, our findings may be generalizable to other Canadian M.D.-Ph.D. programs. Although the study population is small, our survey depicts 
TABLE 2: Medical specialties pursued by M.D.-Ph.D. alumni.

\begin{tabular}{lc}
\hline Medical specialty & $n(\%)$ \\
\hline General surgery & $4(13.3)$ \\
Internal medicine \& subspecialties & $4(13.3)$ \\
Psychiatry & $4(13.3)$ \\
Anatomical pathology & $2(6.7)$ \\
Emergency & $2(6.7)$ \\
Nuclear medicine & $2(6.7)$ \\
Obstetrics/gynecology & $2(6.7)$ \\
Ophthalmology & $2(6.7)$ \\
Pediatric neurology & $2(6.7)$ \\
Pediatrics & $2(6.7)$ \\
Public health \& prev. medicine & $2(6.7)$ \\
Radiology & $2(6.7)$ \\
\hline
\end{tabular}

the success of this training route in producing impactful physician-scientists that are being retained in Canada. Indeed, the outstanding productivity of surveyed clinicianscientists is highlighted both by the very high success rate in grant applications and by a mean $H$-index of 18 . The latter is considerable, given that the average $H$-indices in science, based on a Canadian education policy think tank [12], are lower than 10 . Moreover, while only $9.4 \%$ of Ph.D. students in life sciences remain in academia [13], our study showed that two-thirds of posttraining alumni who responded to the survey are leading a research team in major academic centres. Lastly, our alumni scattered across a spectrum of medical specialties, consistent with previous American studies [14].

The CIHR M.D.-Ph.D. stipend has been an important financial support for students, whereby nearly $80 \%$ of our alumni depended on it at some point of their M.D.-Ph.D. training. Considering the lengthy clinician-scientist training (13-15 years postsecondary), having secure scholarships at the early stage can alleviate financial concerns from young trainees. CIHR was offering $\$ 22,000$ (CAD) per M.D.-Ph.D. student per year and this figure has not been changed in the past 10 years. In comparison, the American Medical Scientist Training Program (MSTP), the US equivalent of the M.D.$\mathrm{Ph}$.D. program, provides an annual stipend between $\$ 22,000$ and $\$ 33,000$ (USD) [15]. The MSTP fund maintains a rising trend [16].

There are some limitations in our study. M.D.-Ph.D. programs are not the only pathway that cultivates clinicianscientists. Other existing programs include the integrated Clinician-Investigator Program (CIP), where medical residents pursue an M.S. or Ph.D. degree during residency training, as well as M.D.-M.S. programs offered by some Canadian medical schools.

We tried to compare the relative successes between clinician-scientists at McGill University who went through an M.D.-Ph.D. program and those who did not. However, since we do not have the complete recruitment data from four major hospitals and five affiliate hospitals of McGill University Health Centre, it is quite difficult to ascertain clinician-scientist recruits between 1999 and 2015 from nonM.D.-Ph.D. programs. An alternate approach we attempted was to estimate the number of clinician-scientists hired at McGill using the Fonds de Recherche du Québec-Santé (FRQS) chercheurs-boursiers cliniciens Junior 1 (defined as $0 \sim 3$ years of research experience) awards and found that there have been 50 individuals who have received this between 2009 and 2015. Fully 30\% of these individuals had both M.D. and Ph.D. degrees (none were trained in M.D.-Ph.D. programs), while the rest had M.D. only (22\%), had M.D.M.S. (32\%), had M.D.-M.P.H. (4\%), or did not have M.D. (10\%). Although we expected to have few to no M.D.-Ph.D. graduates in this population since they only make up a small fraction of the recruitment pool ( $<3 \%$ of graduating class), it was clear that defining the recruiting pool is more complex than anticipated.

This led to the first of several issues arising in comparing relative successes. We could not estimate success in attaining an academic position (which was $100 \%$ among M.D.Ph.D. graduates who responded to our survey), because we could not easily define the population seeking academic positions (i.e., not all M.D. graduates are aiming for academic positions). Second, not all clinician-scientists receive FRQS chercheurs-boursiers cliniciens awards, and this may bias the relative success towards individuals who are already more successful. As individuals recruited from 1999 to 2015 would be early- to mid-career investigators, we would not capture the attrition of hopeful clinician-scientists who fail to attain or maintain funding and end up solely focusing on clinical work. Finally, the database only dates back to 2009, making it difficult to determine recruits between 1999 and 2008.

Lastly, individuals who have been successful in their careers may be more prone to respond to the survey; therefore, certain indicators of academic success may be overestimated. As mentioned above, $65.2 \%$ of posttraining alumni replied to our survey (nonrespondents $34.8 \%$ ). If we assumed all nonrespondents have not remained in academia, the percentage of alumni attaining an academic position would drop from $100 \%$ to $65.2 \%$, which is still quite high compared to only $7 \%$ of US doctors employed in academia [17].

\section{Conclusions}

Together, our observations indicate that the current M.D.$\mathrm{Ph}$.D. system is an effective and economical way of producing competent physician-scientists in Canada. We hope this survey will encourage broader outcome tracking initiatives by other Canadian M.D.-Ph.D. programs.

\section{Competing Interests}

The authors declare that they have no competing interests.

\section{Authors' Contributions}

Tianwei E. Zhou and Paul A. Savage contributed equally to this work. Dr. Mark J. Eisenberg is McGill M.D.-Ph.D. Program Director. 


\section{Acknowledgments}

The authors are grateful for the valuable input from all the interviewed alumni. They also wish to thank Ms. Jennifer Nemes for providing information about McGill's M.D.-Ph.D. program and Ms. Renée Atallah for editorial assistance. Paul A. Savage is the recipient of a Vanier Canada Graduate Scholarship. Tianwei E. Zhou is the recipient of CIHR M.D.-Ph.D. Scholarship and Fonds de Suzanne VéronneauTroutman.

\section{References}

[1] P. C. Webster, "CIHR cutting $\mathrm{MD} / \mathrm{PhD}$ training program," Canadian Medical Association Journal, vol. 187, no. 12, pp. E381E382, 2015.

[2] R. T. Lewinson, C. A. Beers, L. C. Capozzi, V. Iablokov, M. B. Keough, and M. A. Peplowski, "The Canadian MD/PhD training program needs reinstated support," Nature Medicine, vol. 21, no. 10, p. 1111, 2015.

[3] D. D. Twa, J. W. Squair, M. A. Skinnider, and J. X. Ji, “The Canadian clinician-scientist training program must be reinstated," The Journal of Clinical Investigation, vol. 125, no. 12, pp. 43174319, 2015.

[4] C. T. Appleton, J. Belrose, M. R. Ward, and F. B. Young, "Strength in numbers: growth of Canadian clinician investigator training in the 21st century," Clinical and Investigative Medicine, vol. 36, no. 4, pp. E163-E169, 2013.

[5] J.-Y. Yoon, T. Appleton, M. J. Cecchini et al., "It begins with the right supervisor: importance of mentorship and clinicianinvestigator trainee satisfaction levels in Canada," Clinical and Investigative Medicine, vol. 36, no. 6, pp. E269-E276, 2013.

[6] Physician-Scientist Workforce Working Group Report, National Institutes of Health (NIH), Bethesda, Md, USA, 2014.

[7] Canadian Institutes of Health Research, "Canada'sStrategy for Patient-Oriented Research (SPOR)," 2013, http://www.cihr-irsc .gc.ca/e/47693.html.

[8] P. A. Savage, T. E. Zhou, and M. J. Eisenberg, "CIHR MD/PhD cuts: depleting the physician-scientist pipeline at what cost?" Canadian Medical Association Journal, 2016.

[9] Association of American Medical Colleges (AAMC), The State of Women in Academic Medicine: The Pipeline and Pathways to Leadership, 2013-2014, Association of American Medical Colleges (AAMC), Washington, DC, USA, 2015.

[10] T. Nielsen, B. Wallden, C. Schaper et al., "Analytical validation of the PAM50-based Prosigna Breast Cancer Prognostic Gene Signature Assay and nCounter Analysis System using formalinfixed paraffin-embedded breast tumor specimens," BMC Cancer, vol. 14, no. 1, article 177, 2014.

[11] M. Jermyn, K. Mok, J. Mercier et al., "Intraoperative brain cancer detection with Raman spectroscopy in humans," Science Translational Medicine, vol. 7, article 274, Article ID 274ra219, 2015.

[12] Back to Bibliometrics. Higher Education Strategy Associates (HESA), 2015, http://higheredstrategy.com/page/2/?s=h-index.

[13] National Science Foundation, 2011, http://www.nsf.gov/statistics/sed/2011/data_table.cfm.

[14] L. F. Brass, M. H. Akabas, L. D. Burnley, D. M. Engman, C. A. Wiley, and O. S. Andersen, "Are MD-PhD programs meeting their goals? An analysis of career choices made by graduates of
$24 \mathrm{MD}-\mathrm{PhD}$ programs," Academic Medicine, vol. 85, no. 4, pp. 692-701, 2010.

[15] National Institutes of Health (NIH), Medical Scientist Training Program (MSTP) Institutions, 2015, https://www.nigms.nih .gov/Training/InstPredoc/Pages/PredocInst-MSTP.aspx.

[16] D. B. Jeffe, D. A. Andriole, H. D. Wathington, and R. H. Tai, "Educational outcomes for students enrolled in MD$\mathrm{PhD}$ programs at medical school matriculation, 1995-2000: a national cohort study," Academic Medicine, vol. 89, no. 1, pp. 8493, 2014.

[17] P. Miller, T. H. Thrall, T. Norbeck et al., Health Reform and the Decline of Physician Private Practice, 2010, http://www.physiciansfoundation.org/uploads/default/Health_Reform_and_the_ Decline_of_Physician_Private_Practice.pdf. 


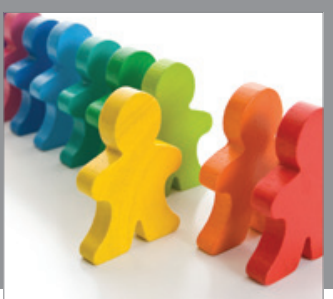

Autism

Research and Treatment
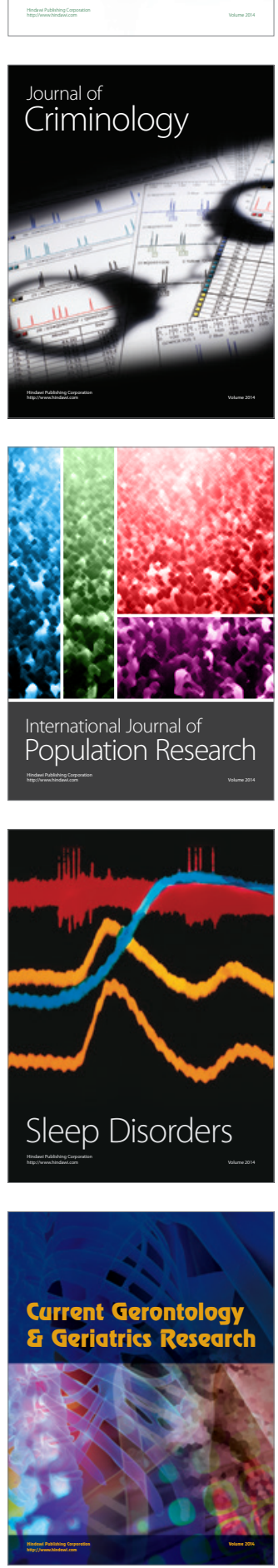

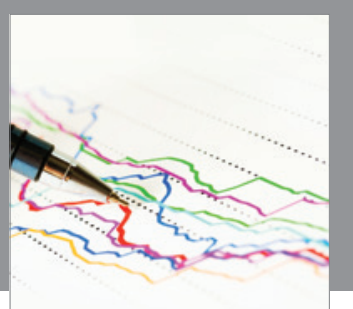

Economics

Research International
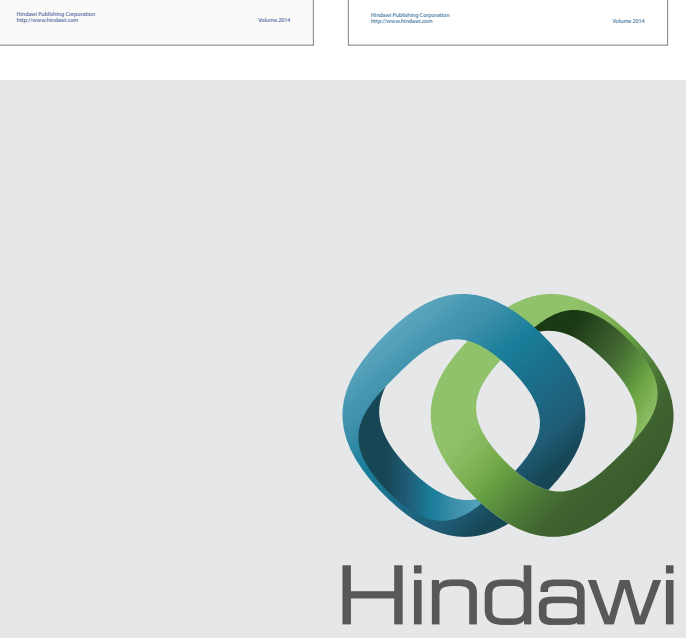

Submit your manuscripts at

http://www.hindawi.com
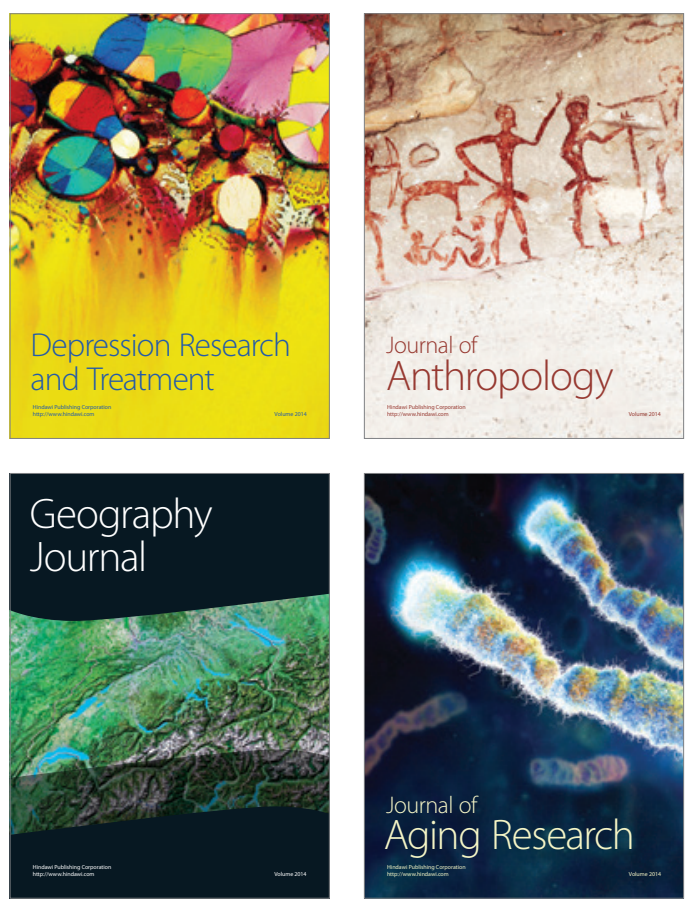
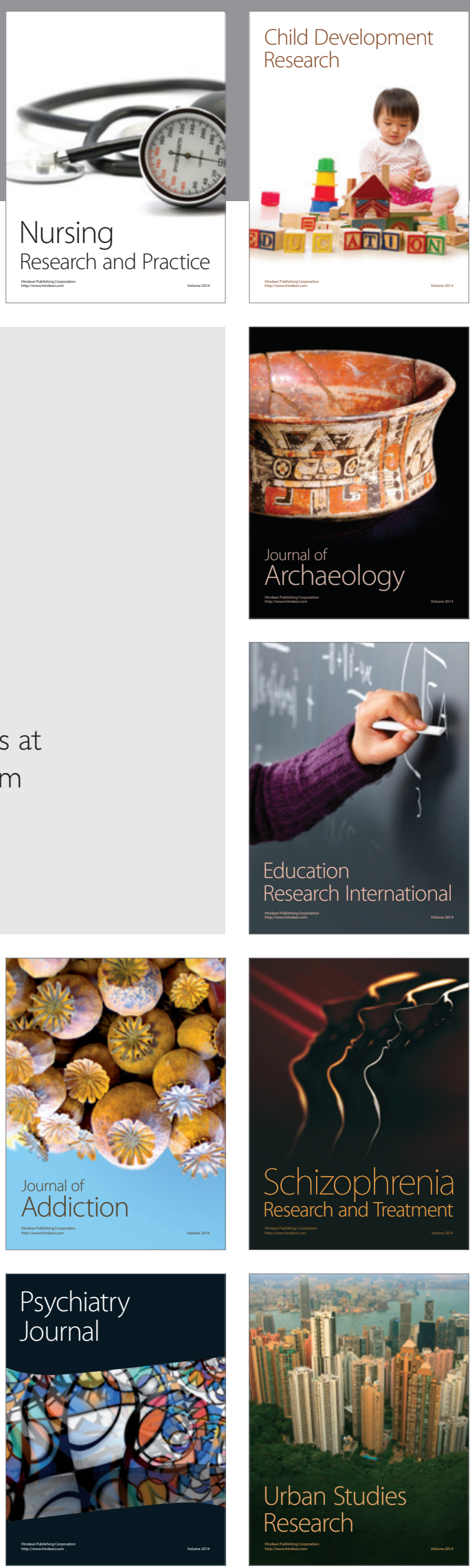